BenthAM OPEN
CrossMark
Content list available at: www.benthamopen.com/TOMEJ/

\title{
Design and Test of a Solanaceae Grafting Robot
}

\author{
Qun Sun*, Ying Zhao, Anfu Guo, Dongjie Zhao and Chong Wang \\ School of Mechanical \& Automotive Engineering, Liaocheng University, Liaocheng, 252059, China
}

\begin{abstract}
A grafting robot based on cleft grafting method has been developed to improve efficiency of grafting solanaceae vegetables. This robot consists of four parts including a clamping manipulator and carrying, cutting, feeding mechanisms. These not only enable the robot to conveniently perform clamping, carrying, positioning, cutting, joining, and binding rootstock and scion, but also improve the grafting efficiency. The average success rates for cutting rootstock, cutting scion and conjugation are $98.7 \%, 99.0 \%$ and $59.6 \%$ respectively. The developed robot was able to perform steady operations, suggesting potential value for practical applications.
\end{abstract}

Keywords: Automatic grafting, cleft graft, grafting robot, solanaceae vegetable.

\section{INTRODUCTION}

Vegetable grafting technique, a vital way toguarantee stable and high yield of plants, has been widely adopted around the world. Since vegetable grafting strongly depends on timing, a time window that is suitable for grafting is usually very short and precise grafting techniques areoften required. Manual grafting can hardly satisfy these requirements due to the low efficiency, intense work loads, and low survival rates of grafted seedlings. To counteract these problems, a grafting robot has been designed to implementautomatic vegetable grafting operations, to improve the grafting efficiency, reduce labor intensity, improve the survival rates of grafts, and to facilitate the vegetable production scale and industrialization [1 - 10]. For solanaceae, the grafting methods include cleft grafting, attached grafting and parallel grafting. Among these, the cleft grafting method was mostly applied in practical production due to the simplicity in operation. In the past, many reports for solanaceae grafting robot were focused on the attached and parallel grafting methods $[11,12]$. Despite the wide utilization in growing seedling, the cutting process of cleft grafting is relatively complicated and there are still few reports about cleft grafting techniques [13, 14]. Y. Zhao [13] reported horizontal shoot apical meristem and vertical cleft grafting operation part with complicated design. S.B. Tian [15] reported a kind of semiautomatic grafting machine based on multi-station pipeline system for mechanical grafting. However, the automation of this grafting machine still needs to be improved. In order to solve these problems, an automatic grafting robot for solanaceae was designed. Using this robot, holding, carrying, position-setting, cutting, jointing and seedling discharging for rootstock and scion have been successfully achieved.

This paper demonstratesa grafting robot based on cleft grafting technique. Furthermore, it also provides a new approach for enhancing the efficiency of grafting solanaceae vegetables. The average rootstock cutting success rate, average scion cutting success rate and average conjugation success rate were $98.7 \%, 99.0 \%$ and $59.6 \%$ respectively.

\section{GENERAL MECHANICAL DESIGN OF THE SYSTEM}

\subsection{Measurement of Relevant Parameter}

Nutritional pots in round shapes were used for growing scion and rootstock seedlings. The parameters of nutritional pots were measured in advance, including the height, diameters of the bottom and the top surfaces.

\footnotetext{
* Address correspondence to this author at the School of Mechanical \& Automotive Engineering, Liaocheng University, Liaocheng 252059, China; Tel: +86 0635 8239270; Fax: +86 0635 8239968; E-mail: sunxiaoqun97@163.com
} 
The experiments adopted 100 Beinong eggplant rootstocks and 100 Beijing 7-leaf scionsall in their suitable grafting time. Then around the joint surface of scions measure the stem diameter $\Phi$, height $H_{1}$, height of the second main leaf $H_{2}$ and height of the third main leaf $H_{3}$. Diagrammatic sketch and relevant parameters of the eggplant seedlings are shown in Fig. (1) and Table 1.

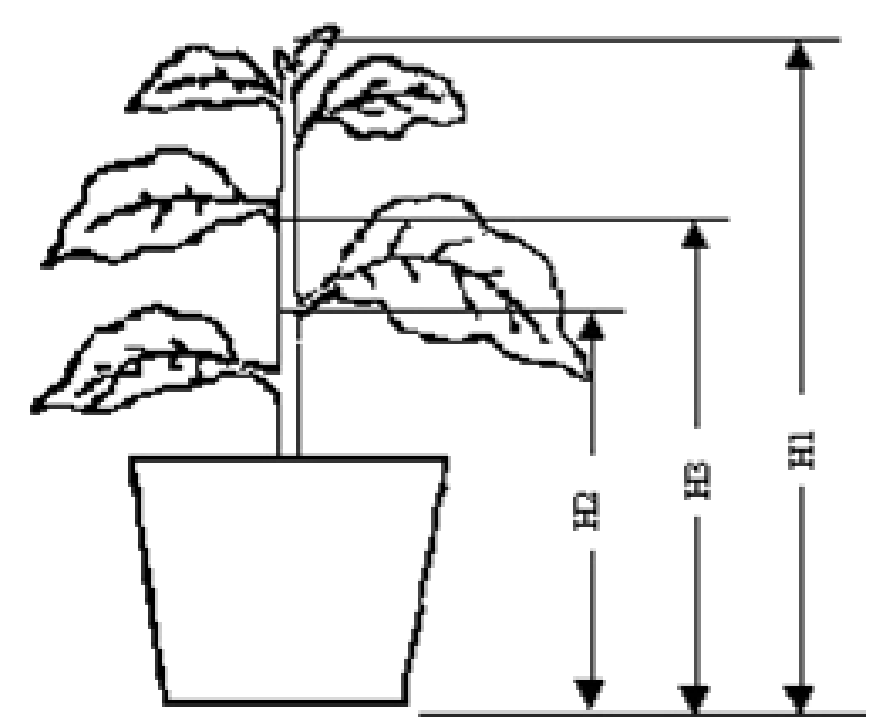

Fig. (1). Diagrammatic sketch of the eggplant seedlings.

Table 1. Relevant parameter of the eggplant seedlings.

\begin{tabular}{|c|c|c|c|c|}
\hline & Diameter $\boldsymbol{\phi}$ & $\mathbf{H}_{\mathbf{1}}$ & $\mathbf{H}_{\mathbf{2}}$ & $\mathbf{H}_{\mathbf{3}}$ \\
\hline mean value of the rootstock & 3.2 & 165.7 & 113.2 & 121.1 \\
\hline standard deviation of the rootstock & 0.35 & 7.85 & 5.23 & 5.90 \\
\hline mean value of the scion & 2.7 & 141.9 & 87.6 & 99.7 \\
\hline standard deviation of the scion & 0.23 & 5.42 & 8.59 & 7.49 \\
\hline
\end{tabular}

\subsection{Working Process of Grafting Robot}

Grafting process by hand was shown in Fig. (2a) [13]. There are 5 6 leaves on the rootstock seedlings which were suitable for grafting. In addition, long and stout stem were also needed. There are 4 5 leaves on a short and thick scion. The bottom of a scion was cut in wedge with the dimension of $1.3 \sim 1.5 \mathrm{~cm}$ and 3 pieces of leaveswere left when grafting began. Position for cutting can be chosen at the thick part of a stem, below the second leave of the rootstock. Interface with the dimension of $1.3 \sim 1.5 \mathrm{~cm}$ was cut in the cross-section center in a downward direction. Wedge cut of scion can be inserted into cambium layer of the interface.

Working process of the grafting robot is shown in Fig. (2b) [13]. The mechanical system of the grafting robot for handling solanaceae grown in nutritional pots mainly consists of three parts: the component for processing rootstock, the component for processing scion, and the common processing device.

\section{DESIGN OF THE MECHANISMS FOR PROCESSING ROOTSTOCK AND SCION}

\subsection{Processing Mechanism for Rootstock}

\subsubsection{Rootstock Manipulator}

The schematic of the rootstock manipulator is shown in Fig. (3). According to the function requirements of rootstock handling, the detailed rootstock manipulator design is shown as following: 
(a) Grafting flow of cleavage-plug method
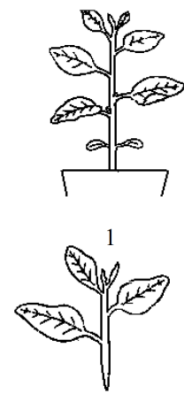

23)

3
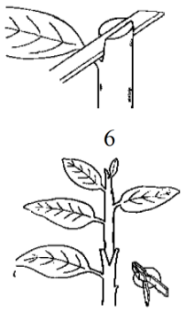

8

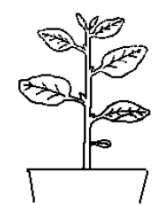

2

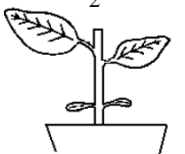

4
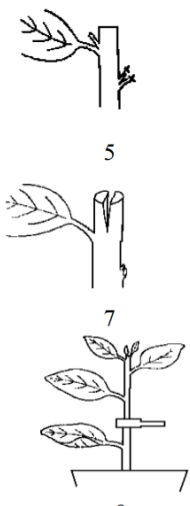

9

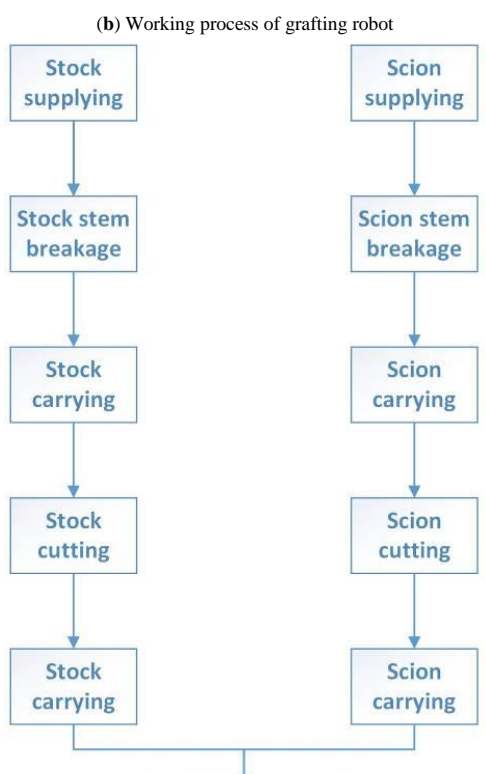

Conjugation

Grafted seedling discharging

1. scion 2. rootstock 3. wedge-shaped cut 4. rootstock stem cutting 5. rootstock remove the leaves

6. rootstock cutting 7. rootstock linear shape cut 8 . conjugation 9. clamping grafted seedling

Fig. (2). Working process of grafting robot.

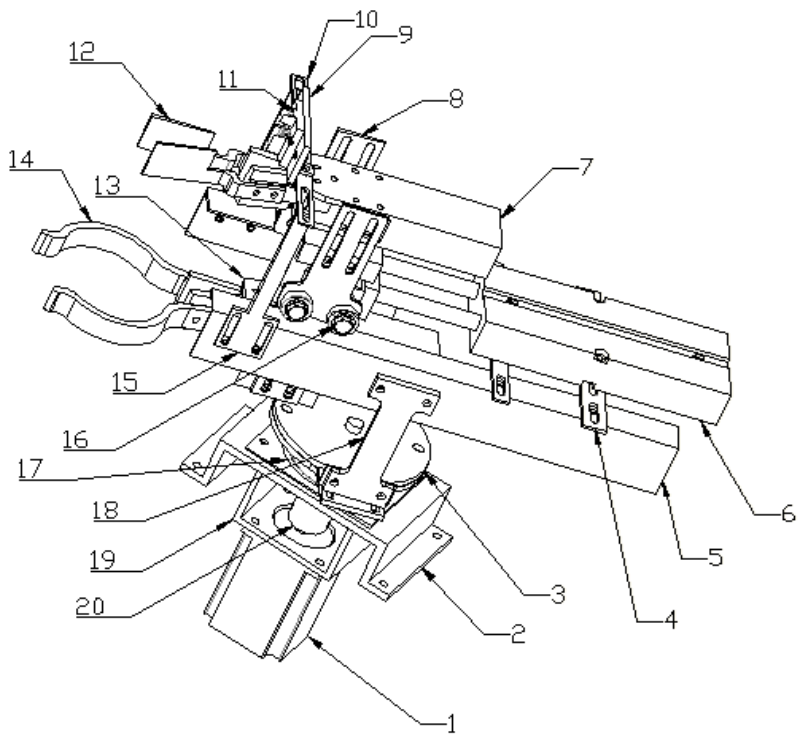

1. stepping motor 2. general supporting stands 3. supporting stands for rotating part 4 . supporting stands for straight acting cylinder 5. straight moving guiding groove 6 . straight acting cylinder 7. top pneumatic claw 8 . pneumatic claw fixed vertical 9 . device to fix the cutter plate 10. horizontal support bar 11. The plate for cutting knife 12. rootstock holder 13. bottom pneumatic claw 14. nutritional pot holder 15. vertical support bar 16 . antifriction bearing 17. pressure-bearing 18. supporting plate for rotating part 19. supporting stands for stepping motor 20 . coupling with the sharp of cinquefoil

Fig. (3). Diagrammatic sketch of rootstock manipulator. 


\subsubsection{Rootstock Manipulator Finger}

Rootstock manipulator consists of two sets of clamping fingers for mechanical rootstock seedling and nutritional pot clamping. The former holds and fixes rootstock seedlings while the latter holds nutritional pots and with stands gravity of the pots and seedlings. The fingers were of pneumatic type, and the major performance indicator, the grasping force, depends on pneumatic pressure and the arm of force, which can be written as:

$$
F=f(p, x)
$$

$F$ - Fingergrasping force $p$-The cylinder pressure $x$ - arm of grasping force

The frictional force between objects and the interior side of the fingers relates to the grasping force, and overcomes the gravity of the pot and seedling. The dry weight of a nutritional pot is $0.1 \mathrm{~kg}$ and the wet weight is $0.2 \mathrm{~kg}$, whilst the total weight including a seedlingis less than $0.3 \mathrm{~kg}$. The total gravity of a nutritional pot is:

$$
G=m g
$$

$G$-the total gravity of nutritional pot; $m$ - the total mass of nutritional pot; g-acceleration of gravity

The friction between the mechanical fingers and a nutritional pot can be expressed as:

$$
f=\mu \mathrm{N}
$$

$f$-Friction between finger interior side and nutritional pot; $\mu$-the coefficient of friction between finger interior side and nutritional pot; $N$ - pressure caused by finger to nutritional pot

The static equilibrium of the nutritional pot is:

$$
f=G
$$

The grasping force can be expressed as:

$$
F \geqq m g / \mu
$$

The grasping force can be enlarged by increasing the coefficient of friction of the finger interior surface or increasing the pressure of the pneumatic cylinder. To avoid excessive grasping force, a throttle valve was fitted on the input end andan elastic seal with high frictional coefficient was fixed on the interior side of the finger. The flow of the throttle valve can be adjusted to provide the best condition for clamping. The same configurations also apply to the rootstock seedling clamping fingers, which should avoid excessive clamping force in order to protect the rootstock seedlings.

\subsubsection{The Plate of Cutting Blade}

A V-shaped cutting blade was employed as the cutting knife in the experiment since the average diameter of the eggplant seedlings was $3.2 \mathrm{~mm}$. To design the cutting knife plate, two vital problems should be considered, whether the seeding isholding up and if the blade can cut off the seedlings completely. Since the distance between the notch of the rootstock and the nutritional pot is larger if the seeding is not completely straight, splints were needed on both sides of a seedling to straighten the seedling. Many experiments prove that the seedlings may not be completely cut off if the splints were purely flat. In order to cut off the seedling a groove was used in the experiment so that cutting can be completed by the feeding difference tothe groove. However, position error may occur during operation of the V-shaped cutting knife due to manufacturing and shock of the mechanical parts. A suitable fuller (wider than the knife) that is $2 \mathrm{~mm}$ deep has been designed to solve this problem. A deeper fuller may destroy the notch whilea lighter fuller cannot complete this step.

\subsubsection{Rootstock Cutting Mechanism}

Fig. (4) shows the schematic of the rootstock cutting mechanism. The rootstock cutting mechanism can lead the cutting blade to finish cutting accurately, and remove excessive seedlings. The cutting blade can perform forward and backward cutting movements led by a dual acting double rod linear cylinder of the rootstock cutting mechanism. The type of the cylinder was chosen to be TPMTN16*50 according to the rootstock manipulator and it can provide $100 \mathrm{~mm}$ 
displacements in two directions. The useful part of the rootstock was below the notch. Liner cylinder and pneumatic claw could be used together to remove the remaining seedlings. A small cylinder 3 leads the pneumatic claw 4 to perform up-and-down movements to separate the two parts. Pneumatic claw 4 cooperates with small cylinder 3 to grab the seedlings.

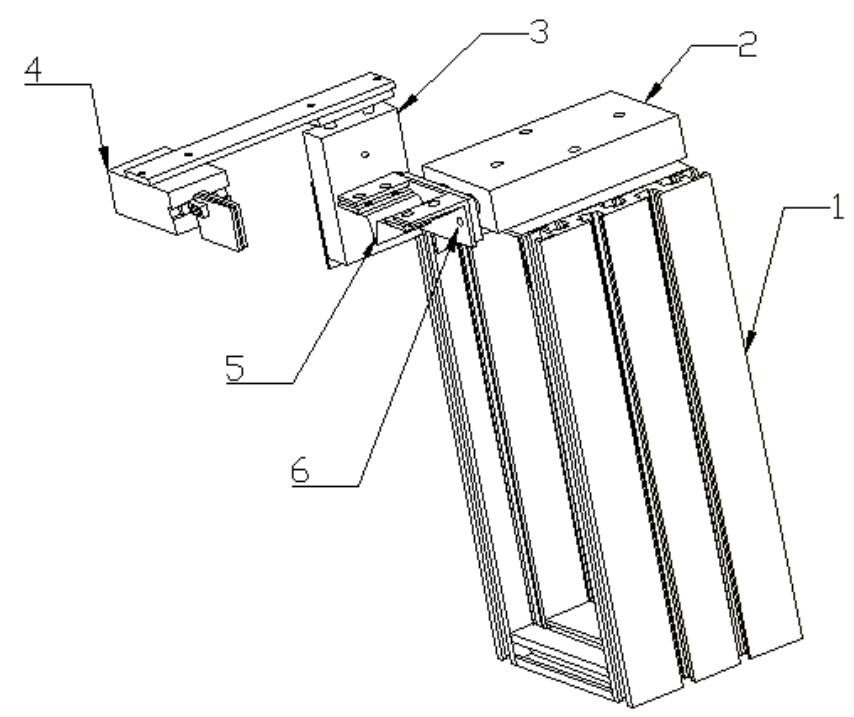

1. type 1590 aluminum 2. straight acting cylinders 3 . small cylinder 4 .

Pneumatic claw 5. V-sharped cutting knife 6 . tool rest

Fig. (4). Schematic of the rootstock cutting mechanism.

\subsection{Scion Processing Mechanism}

\subsubsection{Scion Manipulator}

Fig. (5) shows the schematic of the rootstock manipulator. The function of the rootstock manipulator was to clamp the scion seedling without damaging the seedling and to carry it to a corresponding work position.A circular cylindrical coordinate was used to design the scion manipulator, which consists of horizontal manipulator and a base of the manipulator. The same structure of the scion manipulator is similar to that of the rootstock manipulator. The structural design is the same as that of the rootstock manipulator apart from a nutritional pot clamper.

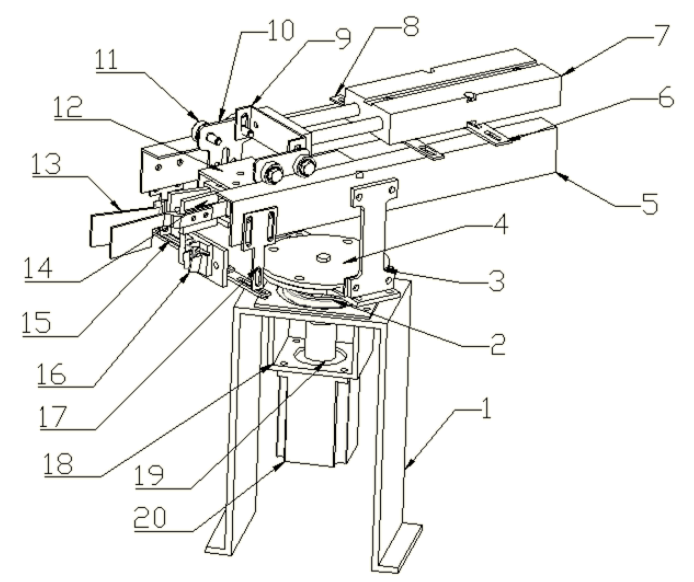

1. general supporting stand 2. pressure-bearing 3 . The rotating part of the support plate 4 . The rotating part supporter 5 . straight moving guiding groove 6 . back supporting stands for straight acting cylinder 7 . straight acting cylinder 8 . front supporting stands for straight acting cylinder 9 . The cylinder connecting rod 10 . vertical plate to fix the pneumatic claw 11 . Rolling bearing 12. base of pneumatic claw 13. The clamping plate of scion 14. pneumatic claw 15 . horizontal support bar 16 . The plate for cutting knife 17. vertical support bar 18. supporting stands for stepping motor 19 coupling with the sharp of cinquefoil 20. stepping motor

Fig. (5). Schematic of the rootstock manipulator. 
It is important to select an appropriate step motor as the driving device for the rotating manipulator base. In view of the torque-frequency of the step motor, the maximum torque acting on the step motor has been calculated. According to the laws of the axial rotation of a rigid body:

$$
M_{z}=J_{z} g \frac{d \omega}{d t}
$$

$Z$ - The axis of rotation of a rigid body $M_{z}$ - torque of external force to the axis of rotation

$J_{z}$ - rotational inertia of rigid body to the axis of rotation $\omega$ - angular rate of the rigid body

Angular velocity of the step motor can be expressed as below:

$$
\omega=f(t) g \frac{\alpha \pi}{180^{\circ}}
$$

$\omega$ - angular velocity of step motor $f(t)$ - pulse frequency of step motor $\alpha$ - Step angle of step motor

The maximum output torque of the step motor can be expressed as follows:

$$
M=\frac{M_{z}}{\eta}
$$

$M$ - practical output torque of step motor $M_{Z}$ - theoretical output torque of step motor $\eta$-overload coefficient $(\eta=0.5 ; 0.7)$

A 57BYG250-76 step motor was employed as the electric motor. It is a two-phase hybrid electric motor with many advantages such as easy control, miniature size, high torque and small vibration.

\subsubsection{Scion Cutting Mechanism}

Fig. (6) shows the schematic of the scion cutting mechanism. The function of scion cutting mechanism was to lead the cutting knife to finish cutting accurately, and to remove the remaining seedlings. The cutting blade can perform forward and backward cutting movements led by a dual acting double rod linear cylinder. The type of the cylinder was again chosen to be TPMTN16*50. The useful part of the scion was above the notch. Straight acting cylinder and pneumatic claw could be used together to remove the remaining rod. Small cylinder 6 leads the pneumatic claw 5 to move up-and-down to finish the separation of the two parts. Pneumatic claw 5 and small cylinder 6 were used together to grab the seedlings.

\section{DESIGN OF CLAMP FEEDING MECHANISM}

First, use a purchased grafting clip to arrange seedlings in order, and then carry this grafting clip to the push clamp position and hold seedlings by the clamping device. The automatic sorting device of the grafting clip is an electromagnetic vibration disc, consisting of a vibration plate, an electromagnet, an armature, a spring piece, a mounting seat, and a damping rubber pad. The pulse current produced by a controller has the same natural frequency as the system and can excite the electromagnet. The system is then led to resonance so that the armature and vibration plate will be quickly pulled to the magnet [15].

The function of the push and clamp mechanism was to push the grafting clip, while the clip is open, from its original position to the position that the scion and rootstock are to be fitted. Then the clip is closed to bite the fitting parts of rootstock and scion. Finally, the push and clamp mechanism is reset. The movement of the clip should be gentle in order to protect the grafted seedling. Therefore, the mechanical device should meet the requirements as follows: the grafting clip remains open with the largest angle which forms the original position to the position that the scion and rootstock are fitted; a buffer device is needed to reduce the impact caused by the close operation of the grafting clip. According to the requirements of the function of the push and clamp device, the design of the push and clamp mechanism includes the following aspects: 


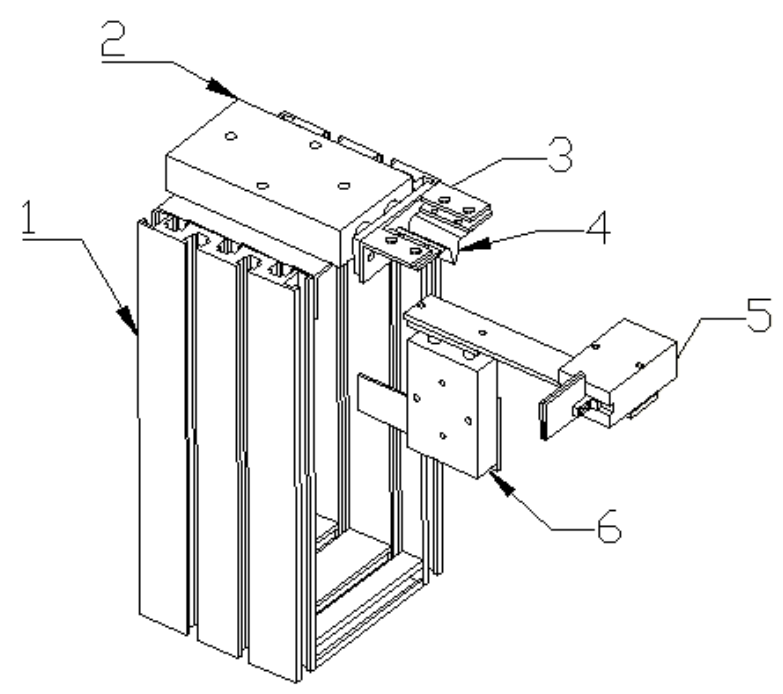

1. type 1590. aluminum 2. straight acting cylinder 3. tool rest 4. V-shaped cut 5. pneumatic claw 6 . small cylinder

Fig. (6). Schematic of the scion cutting mechanism.

\subsection{Sliding Block and the Plate of Guiding Groove}

The plate of guiding groove and the sliding block plays a vital role to the push and clamp mechanism. According to the tail shaped size and the chronological order, the plate of guiding groove and the sliding block were designed. The left and right sides were symmetric for the guiding groove and the sliding block.

\subsection{The Push Rod and the Seat}

The function of the push rod was to push the grafting clip to the clamping position carefully and return to the original position. Due to the sharpness of the grafting clip, the thrust of the push rod only depends on the spring coil of the grafting clip and the cutting groove.

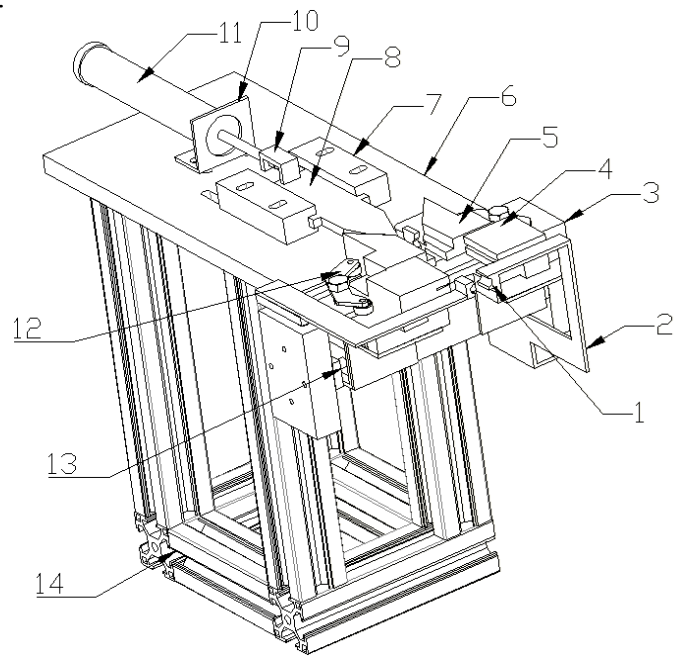

1. pad for hold up the seedlings 2. bracket for hold up the seedlings 3 . Cylinder (vertical) 4. The guide groove plate 5. slide block 6. base 7. base for push rod 8. push rod 9. parts of push rod 10. bracket for cylinder 11. straight acting cylinder 12. turning 13. Cylinder (horizontal) 14. type 3030 aluminum

Fig. (7). Diagrammatic sketch of the push clamping device.

\subsection{Seedling Holding Mechanism}

The position deviation during growth and kinematic error of grafting both can lead the grafted seedling to an 
unsatisfactory position. The mechanism of holding up the seedlings was needed to keep the rootstock and scion pushed by the manipulator to an ideal grafting position before it was bitten by the grafting clip. According to the shape and assembling requirements of each part, the push clamping device would be obtained by assembling all parts. Fig. (7) shows the diagrammatic sketch of the push clamping device.

\section{MECHANISM FOR DISCHARGING GRAFTED SEEDLINGS}

In order to convey grafted seedlings, a mechanism to discharge grafted seedlings was needed. A flat belt conveyor was employed as the conveying mechanism. The prime motor was $24 \mathrm{~V}$ DC stepping motor, veins were needed for increasing the friction force between roller and belt core. The belt core was made of canvas. The width of the belt was decided by the diameter of the nutritional pot, while the coefficient of friction was decided by the speed of DC motor and the mass of the nutritional pot. With the driving chain, the power was conveyed to the driving roller. Fig. (8) shows the diagrammatic sketch of the discharging device.

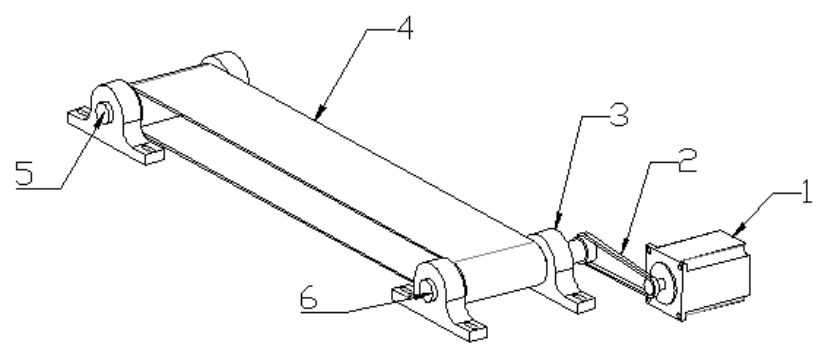

1. Stepper motor 2. Drive chain 3. Base of the bearing 4. Conveyer belt 5 . Driven roller 6. Driving roller

Fig. (8). Diagrammatic sketch of the device for discharging grafted seedlings.

\section{DESIGN OF CONTROL SYSTEM}

\subsection{Overall Control System Design}

The control objects include step motor, direct drive cylinder, LCD display, DC motor and so on. The control system diagram is shown in Fig. (9).

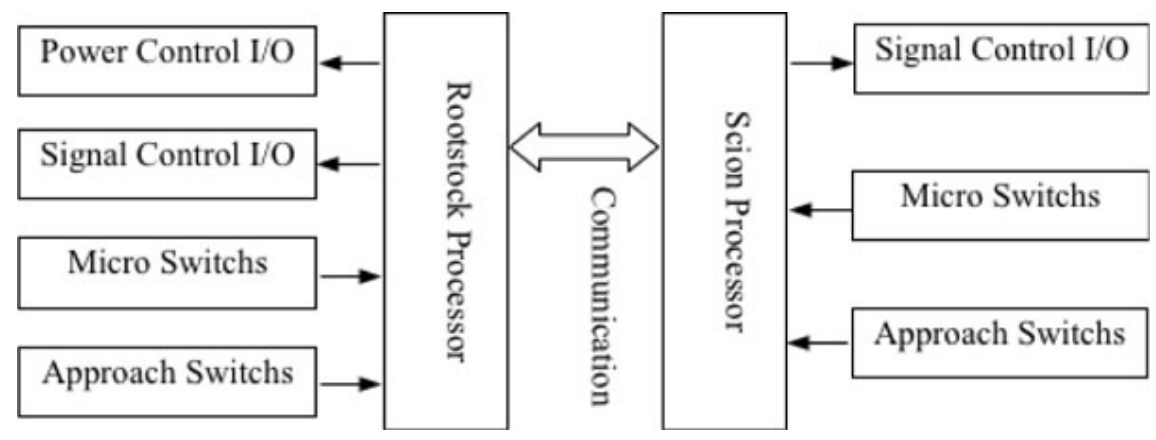

Fig. (9). Structure of the control system.

\subsection{Design of Control System Hardware}

The controller uses Arduino MCU MEGA 2560 and the hardware design is as followed.

The number of the I/O signals are shown in Tables $\mathbf{2}$ and $\mathbf{3}$.

(1) Front channel configurations

The sensors include 1 micro switch and 1 approach switch, both include TTL levels. So, the front channel configurations include 2 way binary input circuit.

(2) Rear channel configurations 
The control system requires 1 servo motors, 2 step motors, 1 DC motor, 7 cylinder and 1 LCD module. The rear channel configurations adopt 4 way step motor control module, 7 way cylinder control module, 1 way DC motor driving module, 1 way relay control module and 1 way LCD driving module.

(3) Exchange channel configurations

The control system is configured with 2 way stock processor communications and 2 way scion processor communications.

Table 2. The stock processor I/O.

\begin{tabular}{|c|c|c|c|}
\hline No. & Control Object Name & I/O Type & Num. \\
\hline 1 & Pneumatic manipulator for Stock & Power drive & 1 \\
\hline 2 & Rotating cylinder for stem breakage of Stock & Power drive & 1 \\
\hline 3 & Stock horizontal cutting cylinder & Power drive & 1 \\
\hline 4 & Stock vertical cutting cylinder & Power drive & 1 \\
\hline 5 & Grafted seedling discharging conveyor belt motor interfaces & Power drive & 1 \\
\hline 6 & grafting seedlings holding and conveying cylinder & Power drive & 1 \\
\hline 7 & manipulator cylinder driving DC cylinder & Power drive & 1 \\
\hline 8 & electric manipulator direction signal & Signal drive & 1 \\
\hline 9 & electric manipulator pulse signal & Signal drive & 1 \\
\hline 10 & Transducer (A) signal input & Signal drive & 1 \\
\hline 11 & Transducer (B) signal input & Signal drive & 1 \\
\hline 12 & Stock processor communicator transmitting end & Signal drive & 1 \\
\hline 13 & Stock processor communicator receiving end & 1 \\
\hline
\end{tabular}

Table 3. The scion processor I/O.

\begin{tabular}{|c|c|c|c|}
\hline No. & Control Object Name & I/O Type & Num. \\
\hline 1 & Scion Pneumatic manipulator & Power drive & 1 \\
\hline 2 & Scion Rotating cylinder for stem breakage & Power drive & 1 \\
\hline 3 & Scion manipulator horizontal cylinder & Power drive & 1 \\
\hline 4 & Scion manipulator vertical cutting cylinder & 1 \\
\hline 5 & vibrator switch & Power drive & 1 \\
\hline 6 & Pallet Seedling supplying motor direction signal & Signal drive & 1 \\
\hline 7 & Pallet Seedling supplying motor pulse signal & Signal drive & 1 \\
\hline 8 & electric manipulator direction signal & Signal drive & 1 \\
\hline 9 & electric manipulator pulse signal & Signal drive & 1 \\
\hline 10 & Scion processor communicator receiving end & Signal drive & 1 \\
\hline 11 & Scion processor communicator receiving end & Signal drive & 1 \\
\hline
\end{tabular}

\subsection{Design of Control System Software}

\subsubsection{Rootstock Processor Main Control Module Design}

The functionalists of the rootstock main control module is to implement stock processing, includes stock robot hand clipping, stock moving,stock inverted ' $\mathrm{V}$ ' shaped cutting. The flow diagram is shown in Fig. (10).

\subsubsection{Scion Processor Main Control Module Design}

The functionality of the scion processor main control module is to implement scion processing, including LCD display, scion robot hand clipping, scion moving and ' $\mathrm{V}$ ' shaped cutting. The program diagram is similar to that of the rootstock processing main control module program.

\section{EXPERIMENTAL DETAILS AND RESULTS}

The experiment used 100 of Beinong eggplant as rootstock and 100 of Seven leaves eggplant as scion, all in their suitable grafting time. Then the samples were randomly divided into 10 groups with 10 per group. The standard of success: 
(1). rootstock and scion bonding well-rootstock and scion centring, pieced together well without deviation;

(2). rootstock and scion bonding moderate-rootstock and scion centring, pieced together moderately with some deviation;

(3). rootstock and scion bonding poor-rootstock and scion centring, pieced together badly with major deviation. It can be seen as successful grafting with "good" or "moderate" comment. Fig. (11) exhibits the prototype of grafting robot.

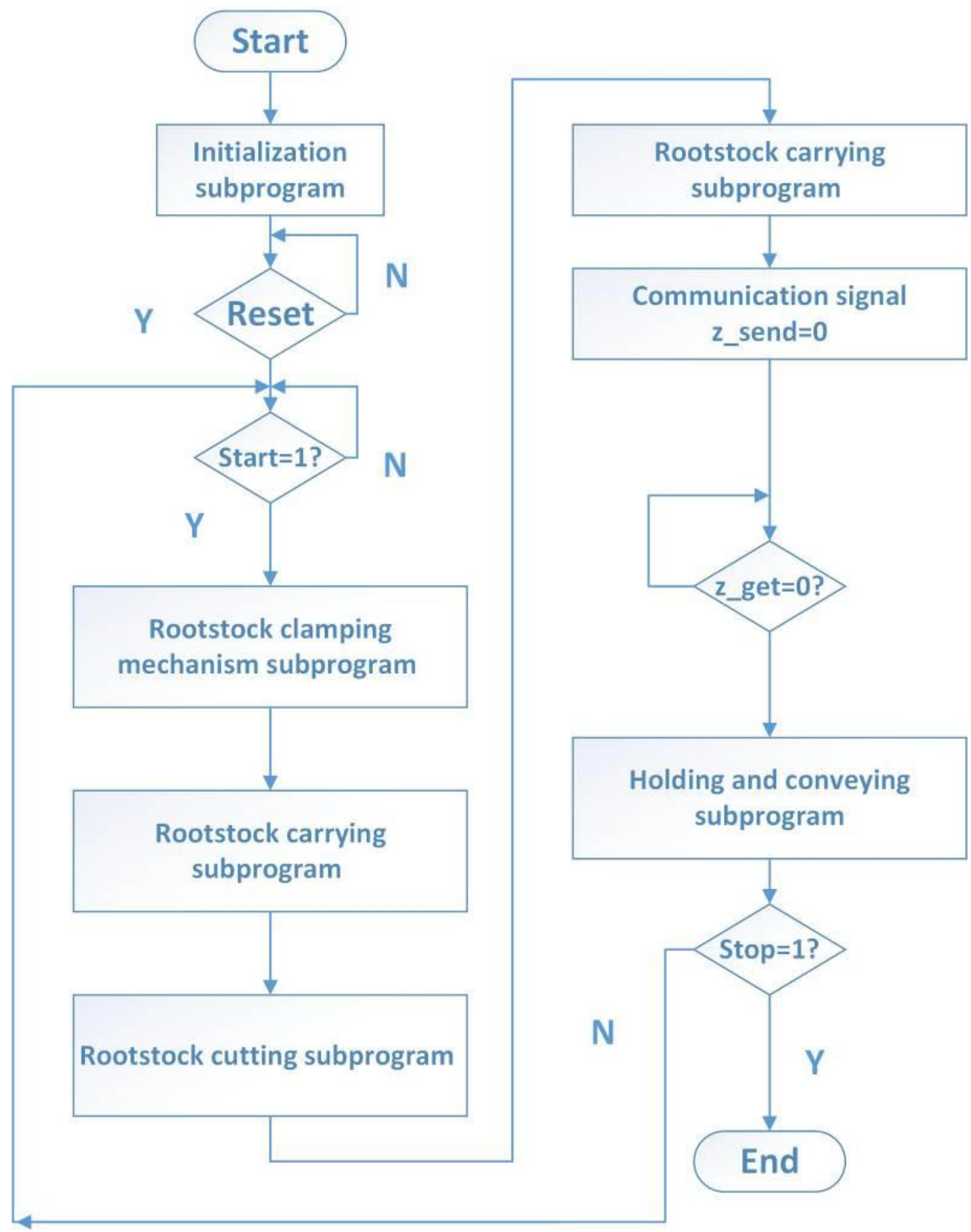

Fig. (10). Flow diagram of stock processing main control module. 


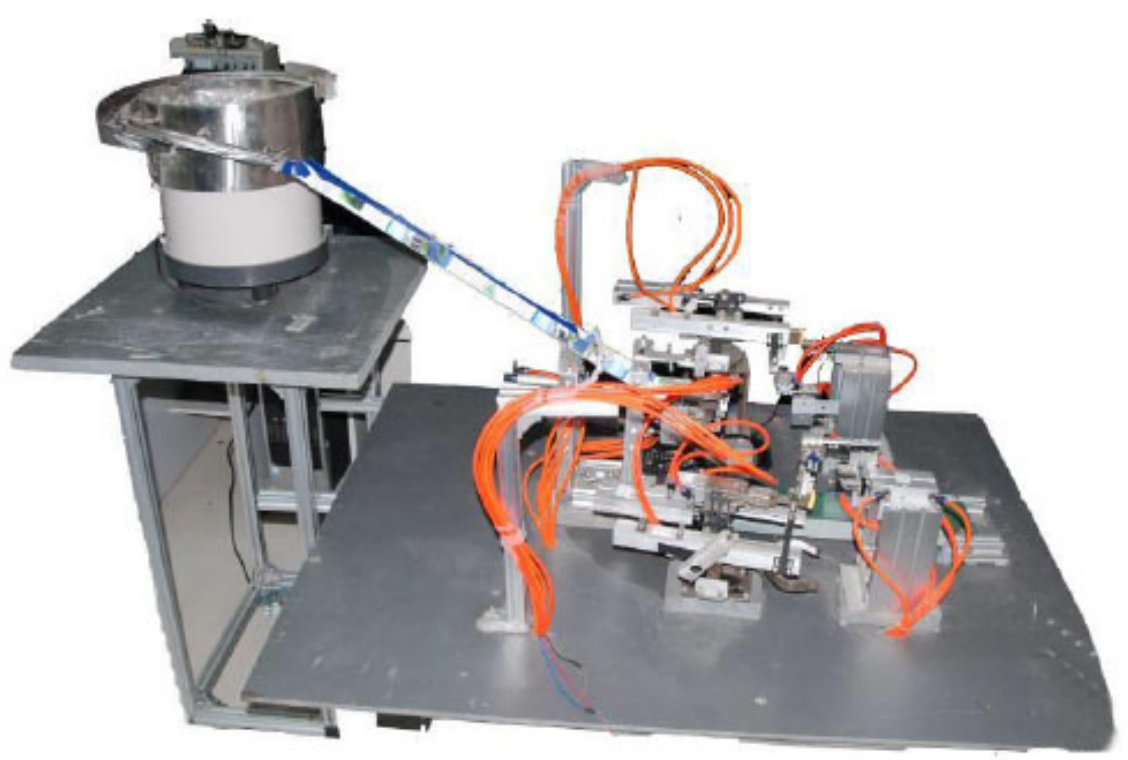

Fig. (11). The prototype of grafting robot.

The results of grafting experiments are shown in Fig. (12). The Results of grafting experiments indicate that the average rootstock notch and the average scion notch with a high rate of success. Due to the winding joint and the individual difference between rootstock and scion, a deviation is ineluctable for alignment of the rootstock and scion.

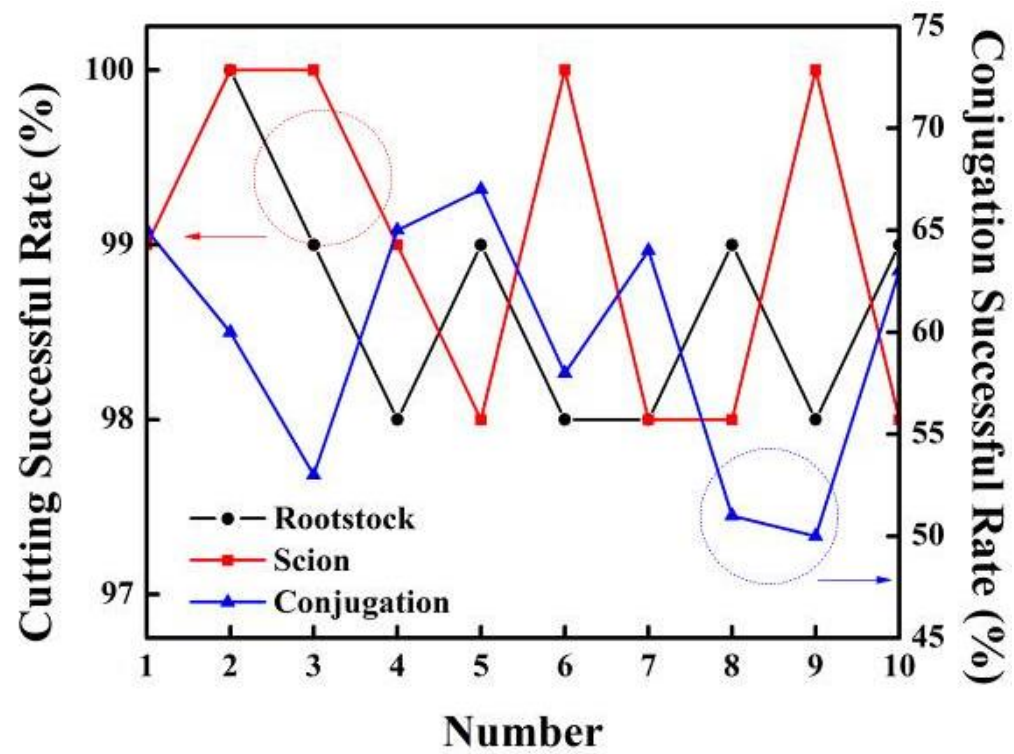

Fig. (12). Results of grafting experiments.

\section{CONCLUSION}

To summarize, a grafting robot for Solanaceous vegetables has been designed according to the manual operation rules of cleft grafting. Furthermore, it also provided a new approach for enhancing and standing Solanaceous vegetables grafting efficiency. The average rootstock cutting success rate, average scion cutting success rate and average conjugation success rate were $98.7 \%, 99.0 \%$ and $59.6 \%$ respectively.

\section{CONFLICT OF INTEREST}

The authors confirm that this article content has no conflict of interest. 


\section{ACKNOWLEDGEMENTS}

This work is supported by the National Natural Science Foundation of China (No.: 51305239), The Natural Science Foundation of Shandong Province (No.:ZR2012CQ026), A Project of Shandong Province Higher Educational Science and Technology Program (No.: JDDLD16) and A Project of Liaocheng City Science and Technology Development Plan (No.: 2013GHZ07).

\section{REFERENCES}

[1] Y. Osamu, and F. Akiko, "Growth adjustment technique of seedling optimal for grafting by seedling storage for cucumber full-automatic machine grafting", Tokyo Agricultural Research, vol. 55, pp. 201-202, 2002.

[2] K. Ken, S. Kenta, and S. Sadao, "Study on automation of seedlings feeding for grafting robot for cucurbitaceous vegetables (part1)-necessary accuracy for cotyledon orienting mechanism", Journal of the Japanese Society of Agricultural Machinery, vol. 68, pp. 117-123, 2006. [http://dx.doi.org/10.1155/2014/604746]

[3] C. Kang, G. Han, T. Noh, H. Choi, and K. Youn, "Splice Grafting Robot for Fruit and Vegetable Plants", World Intellectual Property Organization, Patent WO/2005/089532, 2005.

[4] C. Kang, G. Han, T. Noh, H. Choi, and K. Youn, Splice Grafting Robot for Fruit and Vegetable Plants. Rural Development Administration: Korea, 2005.

[5] J.M. Lee, C. Kubota, S.J. Tsao, Z. Bie, P.H. Echevarria, and L. Morra, "Current status of vegetable grafting robot: Diffusion, grafting techniques, automation", Scientia Horticulturae (Amsterdam), vol. 127, pp. 93-105, 2010 [http://dx.doi.org/10.1016/j.scienta.2010.08.003]

[6] C. Kubota, "Use of grafted seedlings for vegetable production in North America", Acta Horticulturae, vol. 770, pp. 21-28, 2008. [http://dx.doi.org/10.17660/ActaHortic.2008.770.2]

[7] Y.C. Chiu, S. Chen, and Y.C. Chang, "Development of a circular grafting robotic system for watermelon seedlings", Applied Engineering in Agriculture, vol. 24, pp. 1077-1084, 2010 [http://dx.doi.org/10.13031/2013.35904]

[8] Y.C. Chiu, S. Chen, and Y.C. Chang, "Development of a tubing-grafting robotic system for fruit-bearing vegetable seedlings", Applied Engineering in Agriculture, vol. 26, pp. 707-714, 2012.

[9] G.L. Lue, J.P. Li, P.A. Zhu, Q. Li, L.X. Yu, S.M. Zhu, and J.Z. Lou, "Method for rootstock position recognition based on machine vision", Journal of Zhejiang University: Engineering Science, vol. 45, pp. 1766-1770, 2011

[10] J.Z. Lou, J.P. Li, P.A. Zhu, and G. Lü, "Design and test of stock clamping mechanism for vegetable grafting", Transactions of the Chinese Society of Agricultural Engineering, vol. 29, pp. 30-35, 2013.

[11] X. Li, J.P. Li, Z.B. Chen, P. Zhu, and J. Qiu, "Design and test of key mechanism of beveling pin-grafting machine", Journal of Zhejiang University: Agricultural \& Life Science, vol. 39, pp. 663-667, 2013.

[12] K. Jiang, W. Zheng, Q. Zhang, and Q. Feng, "Development and experiment of vegetable grafting robot", Transactions of the Chinese Society for Agricultural Engineering, vol. 28, pp. 8-14, 2012.

[13] Y. Zhao, Q. Sun, and T.Z. Zhang, "Mechanical system design of grafting robot for nutritional bowl eggplant seedlings", Transactions of the Chinese Society for Agricultural Machinery, vol. 38, pp. 94-97, 2007.

[14] K. Liu, Y.L. Yang, K. Li, Q. Chu, and L. Zhong, "Experimental study on rootstock cutting mechanism of pipeline grafting machine for solanaceae", Transactions of the Chinese Society for Agricultural Engineering, vol. 28, pp. 23-28, 2012.

[15] S.B. Tian, J.F. Yang, R.L. Wang, D. Xu, and T. Li, "Optimiza-tion experiment of operating parameters on vibration sorting-clip device for vegetable grafting machine", Transactions of the Chinese Society for Agricultural Engineering, vol. 30, pp. 9-16, 2014.

Received: February 17, 2014

Revised: March 21, 2015

Accepted: June 09, 2015

C) Sun et al.; Licensee Bentham Open.

This is an open access article licensed under the terms of the Creative Commons Attribution-Non-Commercial 4.0 International Public License (CC BY-NC 4.0) (https://creativecommons.org/licenses/by-nc/4.0/legalcode), which permits unrestricted, non-commercial use, distribution and reproduction in any medium, provided the work is properly cited. 